\title{
Ovillo de Ascaris lumbricoides visible en Rayos-X
}

Ball of Ascris lumbricoides visible on X Ray

\section{Juan Rubén Rosa Espinoza*, Carol Alvarado Lemus**}

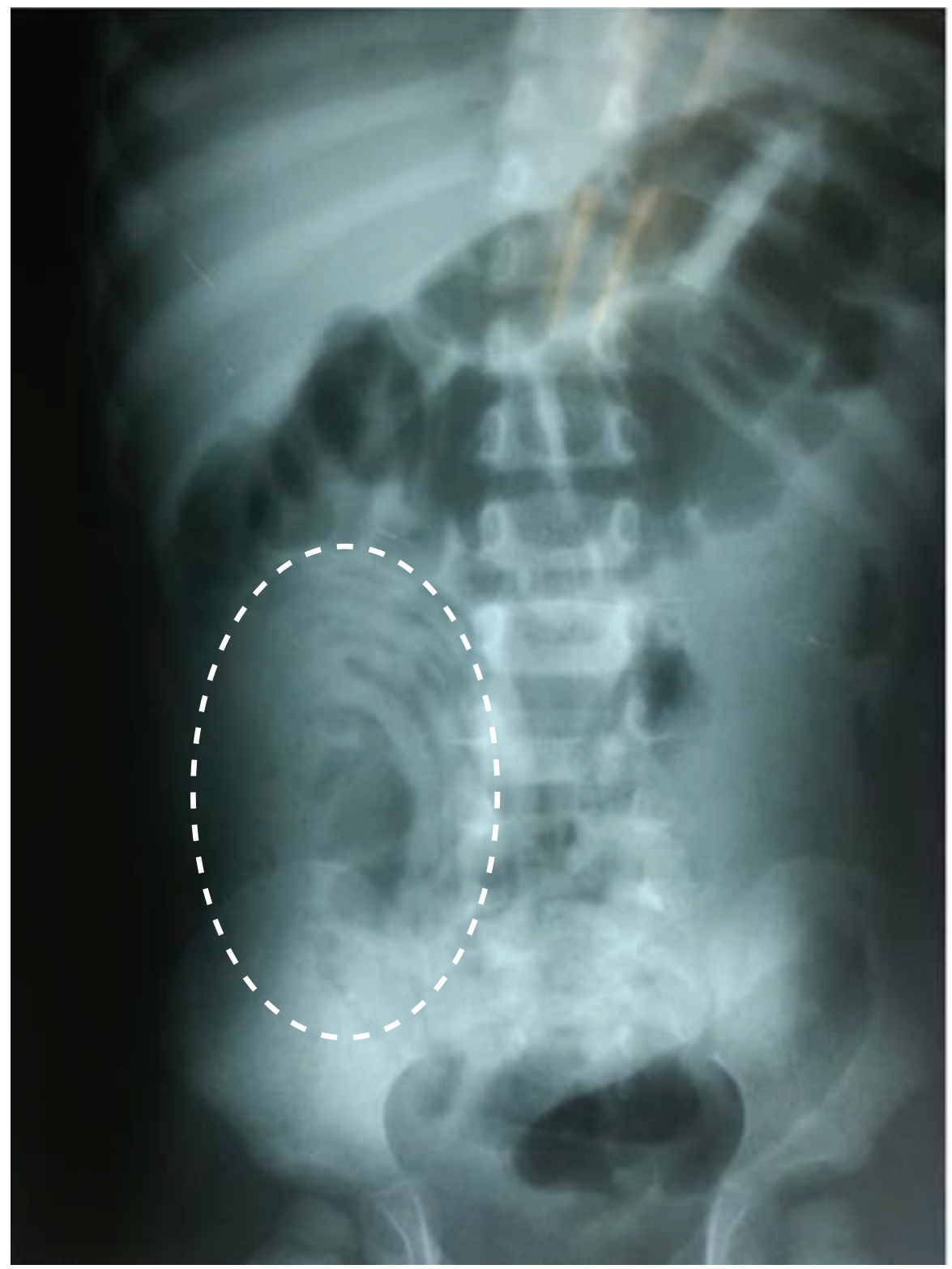

Radiografía simple de abdomen en vista antero posterior, muestra en cuadrante inferior derecho (resaltado en el círculo punteado) una gran

*Residente de Tercer Año Postgrado de Pediatría Universidad Nacional Autónoma de Honduras-Valle de Sula.

**Cirujano pediatra Hospital Nacional Dr. Mario Catarino Rivas Dirigir correspondencia: drjuanrubenrosa@gmail.com

Recibido: 22 de octubre 2016

Aprobado: 02 de febrero 2017 colección de Ascaris lumbricoides adultos en un niño que llegó a la emergencia con cuadro de obstrucción intestinal. La masa de gusanos contrasta con el gas del intestino produciendo una imagen como remolino. Al realizar el acto quirúrgico se encontró la oclusión intestinal a nivel de ĺleon-terminal. 